\title{
PREVALENCE OF PHYSICAL DISABILITY IN SENIOR CITIZENS OF PUNJAB PROVINCE, PAKISTAN
}

Hamid Mahmood ${ }^{a}$, Abdul Rauf ${ }^{b}$, Muhammad Yaqoob ${ }^{c}$, Saleem Rana ${ }^{d}$ aStudent University Institute of Public Health, University of Lahore, Lahore.

${ }^{b}$ Assistant Professor Department of Medicine, Al-Aleem Medical College, Lahore.

${ }^{\mathrm{c}}$ Associate Professor University Institute of Public Health, University of Lahore, Lahore.

'Professor / Director University Institute of Public Health, University of Lahore, Lahore.

\section{ABSTRACT:}

BACKGROUND \& OBJECTIVE: World Health Organization (WHO) considers that Activities of Daily Living ( $A D L)$ is the most important indicator to measure physical and cognitive functions in senior citizens. It is important to know the prevalence of physical disability to find out the needs of senior citizens regarding physical, mental and emotional health. This study has provided us the prevalence rate of physical disability among the senior citizen in the five major cities of Punjab, Pakistan.

METHODOLOGY: This descriptive study was conducted over a period of six months June (06, 2019 to December 05, 2019). The sample was randomly selected. The respondent were senior citizen (Male/Female) having an age of above 60 years. Data were collected from the Index cases. Questionnaire and assessment scales were used as study scale and total sample size was 3675.

RESULTS: The results of study showed that the activities of daily living (ADL) and instrumental activities of daily living (IADL) are related to age, sex, education, social and psychological factors. The facilities of education, job, entertainment, social activities vary from city to city. In all cities a $p$ $=0.05$ was used. In addition, an $\mathrm{E}_{0}=4.5$ was set and the reliability to be used was $95 \%$.

CONCLUSION: It has been concluded that the physical disability in the senior citizens is increasing due to aging population.

KEYWORDS: Frail elderly, Disability evaluation, Risk factors, Prevalence, Aging.

\section{How to cite this:}

doi: https://doi.org/10.37723/jumdc.v11i4.420

Mahmood $\mathrm{H}$, Rauf A, Yaqoob M, Rana S. PREVALENCE OF PHYSICAL DISABILITY IN SENIOR CITIZENS OF PUNJAB PROVINCE, PAKISTAN. jumdc. 2020;11(4):16-24.

doi: https://doi.org/10.37723/jumdc.v11i4.420

This is an Open Access article distributed under the terms of the Creative Commons Attribution License (http://creativecommons.org/licenses/by/4.0), which permits unrestricted use, distribution, and reproduction in any medium, provided the original work is properly cited. 


\section{INTRODUCTION:}

Physical and mental disabilities are problems which the senior citizens face every day. The World Health Organization (WHO) considers that Daily Life Activities (DLA) is the most important indicator to measure functions in the senior citizens. Gallagher and Thompson define "the ability of the individual to carry out essential daily activities". DLA is defined as "the ability to fend for oneself and develop the activities of daily life" ${ }^{[1]}$. Edemekong ${ }^{[2]}$ define DLA as "a set of behaviors whose regular and appropriate execution is necessary for personal care and the maintenance of an independent life".

DLAs are broadly divided into basic daily life activities (BDLA) and instrumented activities of daily living (IADL). The BDLA are those essential skills to carry out self-care activities like, food, dressing, personal hygiene, physiological and other needs. IADL is more complex and necessary to develop an independent life i.e. use of the telephone, making purchases, meal preparation, housekeeping, laundry, use of public transportation, medication self-administration and ability to manage finances.

To measure the DLA, Katz Index (KI) has been used for ADL and the Lawton Index (LI) have been used for IADL. LI introduces a more complex level in the evaluation since it encourages the measurement of aspects that go beyond self-care.

Different researches have been carried out to find out the prevalence and factors which affect the physical disability among the senior citizens throughout world. Different scales and parameters have been used to check the prevalence of physical disability in the senior citizen.

Ministry of Statistics and program implementation, Government of India publish a manual on Physical disability in 2011 describing the future of geriatric cares in the low income countries. He found out that the patron of physical disability and morbidity are the same in Pakistan, India and Bangladesh ${ }^{[3]}$.

Researchers found out that the disability in the urban area was more classified as compared to disability found in the rural area in the United States ${ }^{[4]}$.
Corresponding Author:

Dr. Hamid Mahmood

Student University Institute of Public Health, University of Lahore, Lahore

Email: drhamidmahmood373@gmail.com

In another study, researchers found out that the morbidity due to physical disability in the senior citizens is related to age, sex, education and social interaction ${ }^{[5]}$.

In a cross-sectional study carried out by Barua

${ }^{[6]}$ in Assam, India in 2017 seeking the physical disability patterns and health seeking behavior of the elderly in the urban cities of India. He concluded that the physical disability and the behavior of the senior citizens play a very important role in the development of difficulties in ADL and IADL functions performance.

Lee et al. carried out a community based study in Singapore to find out the reason for physical disability including hearing loss amongst the elderly in a Southeast Asian population. He found out that the physical disability in the old age is related to different factors including educational, psychological and financial integrity of the persons. The activities of daily living and instrumental activities of daily living are widely affected by the social factors and the community influence at large ${ }^{[7]}$.

The heterogeneity in the definitions of physical disability used in different definitions is based on the number of activities which a senior citizen cannot perform properly. If the subject is unable to perform at least one instrumented activity of daily life (IADL), while others define physically disabled persons are those who are unable to perform at least two IADL. A third group of authors states three number of IADL functions must not be performed to declare a person as physically disabled ${ }^{[1]}$.

Despite the information provided by the aforementioned studies, it is necessary to continue conducting research in other contexts of Pakistan at the provincial and national levels with a view to provide useful data for health management. This study will help us to find out the magnitude of problem regarding the prevalence of physical disability in the province of Punjab as well as in Pakistan.

Taking into account the above arguments, it was decided to carry out this research for the 
purpose of increasing the flow of knowledge about the prevalence of physical disabilities in the senior citizens. The results of this research has provided elements for the design of intervention strategies at the individual level, family and community in the population of senior citizens of Lahore, Sargodha, Rawalpindi, Multan and Faisalabad. In addition, the result of this study has provided us valid information for the planning of resources and services. It is expected that the result of this study will influence the organizations of healthcare services to design healthcare services according the prevalence of physical disability among the senior citizens of Pakistan.

The Objectives of the study were:

1- To find out prevalence of physical disabilities in the population under study.

2- To explore the socio-demographic factors that affects the physical disabilities in the study population.

\section{METHODOLOGY:}

This descriptive study was conducted for six months (June, 2019 to December, 2019). The sample was randomly selected. The respondent were senior citizen (male/female) having an age of above 60 years. Data were collected from the Index cases. Questionnaire and assessment scales were used as study scale and total sample size was 3675 .

The samples were randomly selected among the senior citizens from the different cities like Lahore, Sargodha, Rawalpindi, Multan and Faisalabad. For the definitive selection of the sample, the technique called stratified sampling was used. The stratification was done on the bases of different data as defined in the methodology.

A sample size of 3675 was calculated using prevalence of physical disability as $5 \%$ at $2 \%$ margin of error and $95 \%$ confidence level using following formula,

$$
n=\frac{z_{1-\frac{a}{2}}^{2} p(1-p)}{d^{2}}
$$

The ethical approval and IRB approval was taken from University Institute of Public health, University of Lahore, Lahore, Pakistan. This study was carried out among senior citizens of more than 65 years of age, who have any physical disability. The senior citizens who cannot answer properly, their health care providers and family in case of significant cognitive impairment, was asked for consent to participate. The objectives of the study and the importance of their collaboration were explained. They were guaranteed the confidentiality of the information they would provide and the possibility of leaving the study if they so wished, without any impact on the need for further medical attention.

Sample of 728 senior citizens was chosen in Lahore, 698 from Rawalpindi, Multan 700, Faisalabad 701 and Sargodha 866 were selected.

These following instruments have been used to collect the data and make analysis:

1. Minimum Mental State Examination (MMSE) to assess the mental sphere ${ }^{[8]}$.

2. Lawton Index (LI) to assess the physical sphere.

The instruments were applied with the following sequence:

The MMSE was applied to the senior citizens who scored less than 21 or 24 points was considered to have physical disability.

The LI was applied to the senior citizens who have physical disability but does not have cognitive disability.

MMSE and LI are widely used instruments in gerontological research and have the reliability and validity attributes for their use.

The purpose is to verify the presence or absence of any of the risk factors in the senior citizens. It should be applied only by the health professional, as the time required for its application is short (approximately five minutes).

The application of the different instruments was carried out by a group of students of exceptional performance, by the family doctors of the selected clinics that were motivated by the researchers and by residents of the specialization in psychiatry and physiotherapy. Prior training was conducted for the interviewers of the senior citizens. In order to ensure the collection of information, a quality control was carried out at $10 \%$ of the randomly selected interviews. 
The data was processed using a computerized statistical program SPSS Version 24. In order to control the effect of the population structure by age and sex, the rates were defined by the direct method. The sum of the samples from the study cities were chosen as the type of population. For this purpose, the specific rates were multiplied by the population type of the corresponding category in each case. Finally, the standardized rates were obtained by dividing the sum of the expected disabilities by the total population type.

In all cities a $p=0.05$ was used. In addition, an $E_{\text {o }}$ $=4.5$ was set and the reliability to be used was
$95 \%$. The prevalence was obtained from previous studies carried out globally. A design effect of 1.5 was considered, by which the value of $\mathrm{n}$ was multiplied. A sample drop of approximately $5 \%$ was estimated.

\section{RESULTS:}

The estimate of the prevalence of physical disability in senior citizens in the cities studied varied from 13.9 to $36.6 \%$, with the extreme values corresponding to the Faisalabad and Multan respectively (Table-I).

Table- I: Prevalence of disability according to Cities.

\begin{tabular}{|c|c|c|c|}
\hline Cities (n) & No. & Rate & C.I (95\%) \\
\hline Lahore (728) & 253 & 34.8 & $32.6-37.0$ \\
\hline Sargodha (866) & 305 & 35.2 & $32.0-38.4$ \\
\hline Rawalpindi (698) & 247 & 35.4 & $27.9-42.8$ \\
\hline Multan (688) & 252 & 36.6 & $31.6-41.7$ \\
\hline Faisalabad (695) & 96 & 13.9 & $8.5-19.3$ \\
\hline
\end{tabular}

$\mathrm{n}$ : Number of Senior Citizens, * Per 100 Senior Citizens

To control the possible influence of the variables (age and sex of the population) studied on the physical disability rates which were verified by the direct method. Maximum disability rate is found in Multan city with ADL that is 36.84 and minimum rate is found in Faisalabad that is 13.66 same it is found in Faisalabad that is 14.88 with IADL and maximum is found in Rawalpindi that is 38.99 with IADL (Table-II).

Table-II : Physical disability rates with reference to IADL and ADL.

\begin{tabular}{|c|c|c|}
\hline Cities & ADL & IADL \\
\hline Lahore & 24.61 & 33.92 \\
\hline Sargodha & 36.37 & 34.35 \\
\hline Rawalpindi & 34.84 & 38.99 \\
\hline Multan & 36.84 & 35.41 \\
\hline Faisalabad & 13.66 & 14.88 \\
\hline
\end{tabular}

* Per 100 Senior Citizens

When controlling the age, a significant reduction in physical disability was observed in Lahore regarding ADL and IADL (from 24.61 to $33.92 \%$ ). In the remaining cities, the change was discreet. This allowed us to think that if the cities under study were subject to the same age structure, the prevalence of physical disability in Lahore was lower, although the results cannot be compared with those of Faisalabad. 
In relation to physical disability according to age groups and cities under study, an increase was observed as age increased which became more marked in the geriatric population of Sargodha and Rawalpindi. In the first instance, it rose from $17.1 \%$, in the group of $60-69$, to $82.1 \%$, in the group of 80 and over. While in the second group, it varied from $18.1 \%$, in the old-young group to $83.0 \%$, in the old-old group. There was also a marked increase in physical disability in Faisalabad city, as compare to other cities in the same age group.

The female sex was most prevalent in all the cities investigated, with very similar age groups between the cities of Multan (43.1\%), Sargodha $(41.3 \%)$, Lahore (40.4\%) and Rawalpindi $(39.6 \%)$; while Faisalabad showed a much lower level of disability.
The prevalence of physical disability according to other biological variables and cities is shown in (Table III). The estimation of this disability in patients with post-hip fracture sequel exhibited higher levels compared to that found in patients with chronic diseases, for both high rates were recorded. The highest levels of disability for patients with hip fractures were found in the cities of Faisalabad $(82.0 \%)$, Rawalpindi $(80.0 \%)$, Sargodha (77.8\%) and Lahore (70, $0 \%)$; while for the presence of chronic diseases the highest rates were recorded in Lahore $(41.6 \%)$ and Multan (40.8\%). Both cities showed high levels of physical disability, especially the hip fracture. However, the inaccuracy of the intervals, perhaps due to the small number of senior citizens with this condition, limits the scope of these results.

Table-III: Prevalence of physical disability in the Senior Citizens according to biological variables and Cities.

\begin{tabular}{|c|c|c|c|c|c|c|}
\hline \multirow{2}{*}{ Cities } & \multicolumn{6}{|c|}{ Biological Variables } \\
\hline & \multicolumn{7}{|c|}{ Chronic Diseases } & \multicolumn{3}{c|}{ Post Hip Fracture Sequel } \\
\hline & No. & Rate $*$ & IC (95\%) & No. & Rate * & C.I $(95 \%)$ \\
\hline Lahore & 184 & 41.6 & $39.6-43.6$ & 7 & 70.0 & $44.5-95.6$ \\
\hline Sargodha & 142 & 29.8 & $25.7-33.9$ & 21 & 77.8 & $62.1-93.5$ \\
\hline Rawalpindi & 151 & 32.5 & $20.4-44.6$ & 8 & 80.0 & $46.2-100.0$ \\
\hline Multan & 152 & 40.8 & $34.6-47.0$ & 6 & 66.7 & $46.7-86.7$ \\
\hline Faisalabad & 52 & 13.9 & $11.9-15.9$ & 4 & 82.0 & - \\
\hline
\end{tabular}

* Per 100 Senior Citizens. Its calculation is carried out taking as denominator the total of Senior Citizens of each biological and provincial variable,

The prevalence of physical disability in the senior citizens according to psychosocial variables in the cities studied showed that in the population of Lahore, feelings of loneliness were accentuated with, followed by loss of social role. In the Sargodha population, dissatisfaction with daily activities predominated and loss of social role was recorded. While in Rawalpindi, the feeling of inactivity was highlighted followed by the loss of social role. In Multan, the most affected psychosocial variables were the loss of social role and feelings of loneliness, while in Faisalabad, the dissatisfaction with daily activities and the feeling of inactivity was recorded.

In general, with the exception of the Faisalabad city, high rates were recorded under the variables studied and that the loss of the social role was the most affected. In addition, it is necessary to point out that these variables are presumed risk factors which cannot be seen in isolation, because each older adult may have one or more interrelated factors which may have modified other factors.

The prevalence of physical disability decreased in the senior citizens who have better education and professional skills. The city of Lahore have more educated and professional literate personals, hence they have decrease number of physical disability as compare to other cities.

\section{DISCUSSION:}

Twentieth century presented dramatic changes in the types of diseases that mostly affect the 
health of the population. At present, disability among senior citizens is mainly caused by noncommunicable diseases. Disability is not an attribute that is clearly present or absent in the person but may have varying degrees of severity.

Cooper et al., carried out a research on the multiple physical and mental health comorbidity in adults with intellectual disabilities. He carried out a cross-sectional population based study to find out the links between the physical disability and cognition in the fragile older adults ${ }^{[9]}$. All of these studies used the same methodology and applied the same instruments.

Okoro et al., ${ }^{[10]}$ carried out a research on disability and health care adults. Their research results were found different as compared to our results. The prevalence recorded in this research may show different prevalence due to different number of IADL performance by the senior citizens.

Ahmad \& Hafeez ${ }^{[11]}$ carried out a study in which they found out that the factors effecting disability rate in the elderly person is similar in prevalence in Lahore.

Several authors have pointed out that the dissimilarity of the results reported by different investigations may be due, among other reasons, to the mode of application of the instruments. The disability referred by selfreport is generally lower than that obtained by informants, the definition of disability itself, and the characteristics of the instrument used ${ }^{[12]}$. Of course, these aspects become a source of bias for the measurement of this event, which limits the comparison between the results of different investigations.

Beyond the biological effects of aging, many of the possible risk factors for disabilities begin to occur after the fifth decade of life. The increased risk of physical disability found in this research, in most of the cities studied, in relation to other reports, may be related to the economic crisis that has affected the country since the 1990s with important repercussions on the health status of the senior citizens. Likewise, the improvement of the methodological designs of these investigations could have contributed to a better estimate of the true prevalence of physical disability, which would result in an increase in the estimated value. On the other hand, as it was seen in the previous section, the little difference in the levels of physical disability found between the geriatric populations of Lahore, Sargodha, Rawalpindi, and Multan is related to the differences in the structures by age of these (Table-II). This is likely to add the behavior of other variables not controlled with the procedure used, such as different lifestyles in the populations under study.

The performance of the IADL behaved similarly to what was reported by epidemiological studies carried out in several developed countries, where more disability has been observed for those activities that require greater physical effort and displacement of the senior citizens. In Pakistan, Kemal, ${ }^{[13]}$ carried out a research on disabled population of Pakistan. He found out that the prevalence of physical disability in the urban area of Lahore is due to different socio-demographic factors. The result of the study matches with our study. Physical disability according to age behaved similarly to what was reported in other studies. In another study Sage et al., ${ }^{[14]}$ carried out a cross-sectional study on the disability on the senior citizens of the United States. They observed that up to 75 years old, two thirds of the senior citizens can do all the IADLs, but that this capacity diminishes in half between the 75 to 79 years, and still more from the 85 years of age.

The studies cited indicate that as the years pass and accumulate, the shape and functioning of the human body, the so-called normal aging varies. The decrease in muscle strength has been associated with greater degrees of physical disability. Although physiological functions are affected by the aging process, most senior citizens do not have alterations that strongly influence their physical, intellectual, or social functioning. Before the age of 80 , if it is taken into account that this age group is the one that will grow the most in the coming decades. A marked increase in senior citizens can be predicted which must be taken into account by those who decide health policies for longevity healthier ${ }^{[15]}$. This is a first study carried out on the prevalence of physical disabilities in the senior citizens in Punjab, Pakistan. It has been found out that the prevalence of physical disabilities 
and impairments are unique in senior citizens. The comorbid conditions also increased the prevalence of physical disability in senior citizens. Socio-economic factors also play an important role in the development and sustainability of the senior citizens. South-Asian studies on the physical disability and the study carried out by us have almost the same prevalence rate in the aging population ${ }^{[16]}$. Musculoskeletal diseases like osteoarthritis and osteoporosis in senior citizens always lead to a high prevalence of physical disability in the population ${ }^{[17]}$.

Carey et al. carried out a research to find out health characteristics and consultation patterns of people with intellectual disability. His study was cross-sectional in the British population ${ }^{[18]}$. The analysis of the study showed similar results of prevalence as have been found among the senior citizens of Lahore district.

Robertson et al carried out a systematic review on the health or health care of people with intellectual disabilities ${ }^{[19]}$. The finding on the disability in the senior citizens found in our study in Faisalabad was similar to the correlation on the prevalence, physical disability, and functional limitation among the elderly population in England.

In a cross-sectional study carried out by Kuvalekar and coworkers to check the quality of life among senior citizens with physical disability in Udupi Taluk using ADL and IADL scale ${ }^{[20]}$. The results of the study showing the same pattern of prevalence as were found in our study.

The difference in physical disability for women in relation to men is higher in same age groups, where disability is more frequent. It can also be related to strictly biological causes because there are age-dependent diseases such as Alzheimer's, depression, osteoporosis, osteoarthritis, and hip fracture, among others, highly disabling and females are more vulnerable to them. This high rate of osteoarthritis and osteoporosis has been recorded in the different studies carried out in different populations ${ }^{[21]}$.

The prevalence of physical disability due to post-hip fracture sequel was similar to previous studies ${ }^{[22]}$. These results are consistent with expectations to take into account the serious limitations that these fractures produce and alter in the psychological and social functioning of the senior citizens. We have also found out in this study that the cognitive impairment and physical disability is on the rise with similarity as it is increasing in the other developing countries. It has also been found out that women suffer more from physical disability due to lower muscle and bone mass which increases the chances of bone fractures.

Education level in the senior citizens also plays a very important role in maintaining cognitive and physical ability to perform ADL and IADL. Low education levels ultimately hands up with the poor quality of life scores. Cwirlej-Sozanska et al., ${ }^{[23]}$ carried out research using ADL and IADL as a measuring scale to check the quality of life. The determines used to assess the quality of life was education, socio-economic factors, cultural and interpersonal communication in Poland. He found out that education, socioeconomic cultural norms play a very important role towards the development of physical disability which was quite similar to our present study. It also increases physical disability and cognitive impairment due to comorbid conditions. These results are similar to the previous studies carried out in different countries.

The society sees unemployment in senior citizens as a normal fact. In this study, a rate of physical disability was obtained according to this variable lower than those required by other investigators. With retirement, the senior citizens receive a well-deserved rest, after many years of work ${ }^{[24]}$.

The results obtained regarding feelings of loneliness showed a higher prevalence in Lahore with respect to the other cities. This could be related to the cosmopolitan nature of the capital which generates a more convulsive life, which tends to produce the so-called "distance intimacy", that is, to make the old man feel lonely even when physically surrounded by relatives.

The prevalence of physical disability due to inadequate living conditions did not differ significantly between most of the territories investigated. Faisalabad was exception, for which a much lower rate was registered.

From the study, it has been found out that the prevalence of physical disability may depends on socio-economic, socio-demographic, chronic illness, and social integration of the senior 
citizens.

To the best of our knowledge, this was the first study that has been carried out in the five major cities of Punjab to find out the prevalence rates of physical disability in the urban cities of Punjab.

The limitation of the study is the limited resources available to study comorbid diseases in the senior citizens, the inclusion of healthcare providers, and proper recording of cognitive functions which are a greater contributor to the physical disability.

\section{CONCLUSION:}

It has been concluded that the physical disability in senior citizens is on the increase due to the aging population. There is a need for a more comprehensive in-depth study among the senior citizens in rural and urban areas of Pakistan.

ACKNOWLEDGEMENT: None.

CONFLICT OF INTEREST: All authors disclose no conflict of interest.

\section{GRANT S UPPORT\& FINANCIAL DISCLOSURES: None.}

\section{REFERENCES:}

1. Barthel Index of Activities of Daily Living. 2013 [Cited 2013 December 25]. Available from: http://www.healthcare.uiowa. edu/igec/tools/function/barthelADLs.pdf.

2. Edemekong $P F$, Bomgaars DL, Sukumaran S, Levy SB. Activities of Daily Living (ADLs). Treasure Island (FL): StatPearls Publishing; 2020 [Cite on March 2020]. Available from: https://www.ncbi.nlm.nih.gov/books/NBK 470404/

3. Office of the Registrar General \& Census Commissioner, Ministry of Home Affairs, Disabled population India. 2013. [Cite December 2019]. Available from: http://www.censusindia.gov.in/Census_A nd_You/disabled_population.aspx.

4. Zhao G, Okoro CA, Hsia J, Garvin WS, Town $M$. Prevalence of Disability and Disability Types by Urban-Rural County Classification-US, 2016. American Journal of Preventive Medicine. 2019;57(6):749756. Doi: 10.1016/j.amepre.2019.07.022.

5. Emerson E, Hatton C, Baines S, Robertson J. The physical health of British adults with intellectual disability: cross sectional study. International Journal for Equity in Health. 2016;15(1):1-9. Doi: 10.1186/s12939016-0296-x

6. Barua K, Borah M, Deka C, Kakati R. Morbidity pattern and health-seeking behavior of elderly in urban slums: A crosssectional study in Assam, India. Journal of Family Medicine and Primary Care. 2017;6(2):345-350.

7. Lee JC, Danker AN, Wong YH, Lim MY. Hearing loss amongst the elderly in a Southeast Asian population-A communitybased study. Annals of the Academy of Medicine, Singapore. 2017;46(4):145154. Doi: $10.4103 / 2249-4863.220030$

8. K Upadhyaya A, Rajagopal M, M Gale T. The six item cognitive impairment test (6-CIT) as a screening test for dementia: comparison with mini-mental state examination (MMSE). Current Aging Science. 2010;3(2):138-142.

9. Cooper SA, McLean G, Guthrie B, McConnachie A, Mercer S, Sullivan F, et al. Multiple physical and mental health comorbidity in adults with intellectual disabilities: population-based crosssectional analysis. BMC Family Practice. 2015;16(1):110. DOI: $10.1186 /$ s12875015-0329-3

10. Okoro CA, Hollis ND, Cyrus AC, GriffinBlake S. Prevalence of disabilities and health care access by disability status and type among adults-United States, 2016. Morbidity and Mortality Weekly Report. 2018;67(32):882. Doi:10.15585/ mmwr.mm6732a3external icon

11. Ahmad K, Hafeez M. Factors affecting social participation of elderly people: a study in Lahore. Journal of Animal Plant Science. 2011;21(2):283e289.

12. Shirkhorshidi AS, Aghabozorgi S, Wah TY. A Comparison Study on Similarity and Dissimilarity Measures in Clustering Continuous Data. PLoS ONE. 2015. 10(12):e0144059.

13. Kemal, AR. Disabled Population of Pakistan. In Population of Pakistan: An 
Analysis of 1998 Population and Housing Census. Islamabad: Pakistan Institute of Development Economics, 2003. 327-348.

14. Sage R, Ward B, Myers A, Ravesloot C. Transitory and enduring disability among urban and rural people. The Journal of Rural Health. 2019;35(4):460-470.

15. Duchowny KA, Clarke PJ, Peterson MD. Muscle weakness and physical disability in older Americans: longitudinal findings from the US Health and Retirement Study. The Journal of Nutrition, Health \& Aging. 2018;22(4):501-507. Doi: 10.1007/ s12603-017-0951-y.

16. Williams ED, Cox A, Cooper R. Ethnic differences in functional limitations by age across the adult life course. The Journal of Gerontology: Series A. 2020;75(5):914921. Doi: $10.1093 /$ gerona/glz264

17. Iqbal MN, Haidri FR, Motiani B, Mannan A. Frequency of factors associated with knee osteoarthritis. Journal of the Pakistan Medical Association. 2011;61(8):786-789.

18. Carey IM, Shah SM, Hosking FJ, DeWilde S, Harris T, Beighton C, et al. Health characteristics and consultation patterns of people with intellectual disability: a crosssectional database study in English general practice. British Journal of General Practice. 2016;66(645):e264-270. Doi: 10.3399/ bjgp16X684301

19. Robertson J, Hatton C, Baines S, Emerson E. Systematic reviews of the health or health care of people with intellectual disabilities: a systematic review to identify gaps in the evidence base. Journal of Applied Research in Intellectual Disabilities. 2015;28(6):455-523. Doi: $10.1111 /$ jar. 12149

20. Kuvalekar K, Kamath R, Ashok L, Shetty B, Mayya S, Chandrasekaran V. Quality of life among persons with physical disability in udupi taluk: A cross sectional study. Journal of Family Medicine and Primary Care. 2015;4(1):69-73.
21. Wheaton FV, Crimmins EM. Female disability disadvantage: a global perspective on sex differences in physical function and disability. Ageing \& Society. 2016;36(6):1136-1156. Doi: 10.1017/ S0144686X15000227

22. Dyer SM, Crotty M, Fairhall N, Magaziner J, Beaupre LA, Cameron ID, et al. A critical review of the long-term disability outcomes following hip fracture. BMC Geriatrics. 2016;16(1):158. Doi: 10.1186/s12877016-0332-0.

23. Ćwirlej-Sozańska A, Wiśniowska-Szurlej A, Wilmowska-Pietruszyńska A, Sozański B. Determinants of ADL and IADL disability in older adults in southeastern Poland. BMC Geriatrics. 2019;19(1):1-13.

24. Ostir GV, Carlson JE, Black SA, Rudkin L, Goodwin JS, Markides KS. Disability in older adults 1: Prevalence, causes, and consequences. Behavioral Medicine. 2017;24(4):147-156. Doi:10.1080/ 08964289.1999 .11879271

\section{Author's Contribution}

Hamid Mahmood: Study design, manuscript writing \& proof reading.

Abdul Rauf: Over all supervision of data collection, analysis and manuscript writing.

Muhammad Yaqoob: Help in data collection \& final draft of study.

Saleem Rana: Data analysis \& manuscript writing.

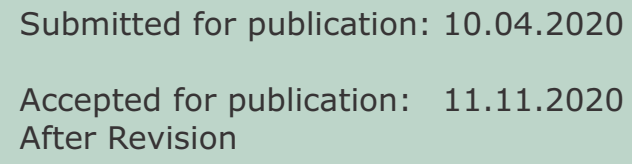

